\title{
EVACUATION SIMULATION IN KALAYAAN RESIDENCE HALL, UP DILIMAN USING GAMA SIMULATION SOFTWARE
}

\author{
Alexis Richard C. Claridades ${ }^{\text {a }}$, Jara Kaye S. Villanueva ${ }^{\text {b }}$, Edgardo G. Macatulad ${ }^{\text {c }}$ \\ ${ }^{a}$ Department of Geodetic Engineering, College of Engineering, University of the Philippines - Diliman \\ (acclaridades@up.edu.ph ${ }^{\mathrm{a}}$, jsvillanueva2@upd.edu.ph ${ }^{\mathrm{b}}$, edgardo.macatulad@coe.upd.edu.ph ${ }^{\mathrm{c}}$ )
}

KEY WORDS: GIS, Geosimulation, Evacuation, GAMA

\begin{abstract}
:
Agent-Based Modeling (ABM) has recently been adopted in some studies for the modelling of events as a dynamic system given a set of events and parameters. In principle, ABM employs individual agents with assigned attributes and behaviors and simulates their behavior around their environment and interaction with other agents. This can be a useful tool in both micro and macroscale -applications. In this study, a model initially created and applied to an academic building was implemented in a dormitory. In particular, this research integrates three-dimensional Geographic Information System (GIS) with GAMA as the multi-agent based evacuation simulation and is implemented in Kalayaan Residence Hall. A three-dimensional GIS model is created based on the floor plans and demographic data of the dorm, including respective pathways as networks, rooms, floors, exits and appropriate attributes. This model is then re-implemented in GAMA. Different states of the agents and their effect on their evacuation time were then observed. GAMA simulation with varying path width was also implemented. It has been found out that compared to their original states, panic, eating and studying will hasten evacuation, and on the other hand, sleeping and being on the bathrooms will be impedances. It is also concluded that evacuation time will be halved when path widths are doubled, however it is recommended for further studies for pathways to be modeled as spaces instead of lines. A more scientific basis for predicting agent behavior in these states is also recommended for more realistic results.
\end{abstract}

\section{INTRODUCTION}

\subsection{Background}

Agent-based modelling breaks down a system into individual components called agents. Agents follow a specific set of rules for their behavior, describing how they interact with their environment and other agents. (Chen, 2006) They can be assigned to be performed simultaneously, or asynchronously (CASA UCL, 2006), and can be applied to various fields for applications.

Macatulad (2014 and 2015), in a paper and master's Thesis demonstrated the ability of Agent-Based Geosimulation for building evacuation. A model was implemented in a simulation software, with the aid of Geographic Information Systems to produce an accurate representation of the environment, and observed the patterns of evacuation of agents inside Melchor Hall, the academic building of the College of Engineering in the University of the Philippines Diliman.

In this study, the said model will be implemented in another building in UP Diliman, Kalayaan Residence Hall, a student dormitory for freshmen students.

\subsection{Objectives and Expected Output}

This paper aims to apply the existing model (Macatulad, Blanco, 2014) in 3D evacuation simulation in another setting using an agent-based simulation platform, GAMA, and in addition, to apply and observe different parameters in the existing platform.
In line with the above, this study will produce a detailed 3Dimensional GIS model of the Kalayaan Dormitory, including its interior network, and a simulation model for evacuation.

\subsection{Study Area}

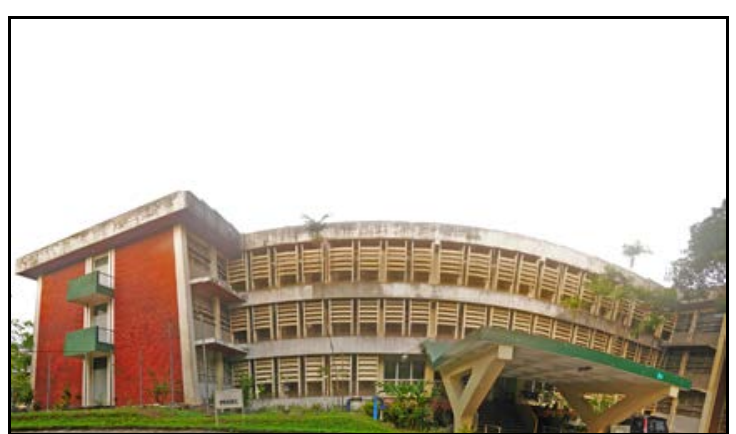

Figure 1. Panoramic view of Kalayaan Residence Hall

The Kalayaan Residence Hall is a dormitory operated by the University of the Philippines, housing 198 male and 344 female freshmen students. It was first opened on the start of classes in 1975, and an annex was added three years after to accommodate more students. (iskWiki, 2012) It operates under the single fee system, where the dorm fee includes meals provided by concessionaires in the dormitory. (UP OVCSA, nd)

The dorm is an H-type building with 4 stores, including one basement, with the corridors assigned either for boys, or for girls. Each of the rooms are provided with basic furnishings including beds and mattresses, cabinets, and a study table. 
Each room has a maximum of 2 residents. (iskWiki, 2012) According to the building's floor plan, there are a total of 16 fire exits, and 1 main entrance/exit. Aside from the residents, resident assistants (RA) are assigned in each division or corridor to monitor the freshmen residents. The dormitory manager and some security personnel are also staying in the Kalay.

\subsection{Scope and Limitations}

This paper will be implementing an existing model created in a previous research, and additions in the investigated parameters will be studied. This model is implemented in version 1.6.1 of the GAMA platform; newer versions were not tested.

The 3D model is based primarily on the floor plan given by the University Office of the Campus Architect. This includes the floor layout, dimensions of the rooms, corridors and spaces, and the entrances and exits. Improvements in the structure since the creation of the plan have not yet been reflected. The number of agents reflected in the simulation reflects only the maximum number of residents in the rooms. Number of available slots, resident assistants, officials and personnel of the dormitory including those of the Office of Student Housing (OSH), have not been reflected.

This study also excludes the open grounds, and considers only the main dormitory building, as agents are assumed to originate from their assigned dorm room. Although rooms are separated for girls and boys, agents' behavior in evacuation will not be differentiated by sex.

\section{REVIEW OF LITERATURE}

\section{$2.1 \quad$ Evacuation Plans}

Evacuation plans are parts of a general emergency response plan of an organization, in response to major emergencies. (CMU, 2016) Issues that must be considered include existing work organization, types of hazards they are at risk, technological system elements, possible outcome states, goals to be achieved, and demographics of people. These plans must be made in accordance with how the system, or the organization will act in times of crisis. (Zarboutis, 2007)

\subsection{Agent-based Modeling and Simulation}

The agent-based approach, as compared to other types of simulation, is capable of capturing emergent phenomena, providing a natural environment, and is more flexible in terms of developing models. In ABM, we describe behaviors and interactions in the system from the bottom up, starting from the individual agents up to the environment itself as a whole. However, since we describe the system at a disaggregated model, we must reach a high level of detail, describing numerous agent behaviors and attributes, including their interactions. (CASA UCL, 2006)

In $\mathrm{ABM}$, the decision rules may vary per agent, as their attributes and behavior rules also vary. Their respective effects on other agents and their environment are then studies afterwards. (Macal, 2006) Their behaviors must be adaptive because they must be able to learn from their environments and change these behaviors accordingly. (CASA UCL, 2006)
In terms of evacuation, ABM provides capabilities to address individual driving characteristics for agents in the simulation. It also provides other relevant information such as speeds, delays, number of evacuees at any given time. (Chen, 2006) It has been studied that human-like models (such as agentbased models based on human behavior) can more closely approximate a genuine evacuation. Some methods in fact, including cellular automata, social force and other similar microscopic models, can be combined to produce more accurate results. (Zheng, 2009)

A combination of an evacuation model and a fire spread model is also important; as effects of fire such as toxic hazards can affect their behavior as they evacuate. (Shi, 2009) Also, aside from indoor evacuations, ABM can also be applicable in a macro scale in cases such as hurricane evacuation. (Chen, 2006). However, results of these kinds of simulations are difficult to verify as it is nearly impossible to conduct very similar and repeatable experiments, and they impede developments in computer simulation models. (Shi, 2009)

\subsection{GAMA Simulation Software}

GAMA, or the GIS Agent-based Modeling Architecture is a modeling platform that gives us the opportunity to use geographic vector data in defining the environment of our simulations. Since GIS is handled in GAMA, it also gives us the ability to connect to databases. (GitHub, 2015)

It uses its own scripting language, GAML. It enables multiscale modeling by enabling representation of emergent agents through its create, update, merge, and dispose operations. An Integrated Development Environment (IDE) also provides users an easier way to learn the language, also present in other languages. (Taillandier, 2012)

\section{METHODOLOGY}

This study utilized GAMA platform in three-dimensional multi-agent evacuation simulation in Kalayaan Residence Hall, University of the Philippines-Diliman. Specifically, this study implemented the previously developed GAMA model for evacuation simulation (Macatulad, 2015).

The main workflow scheme is divided into three phases: Phase I, Phase II, and Phase III. Phase I involves the creation of a three-dimensional model, Phase II focuses on the evacuation simulation using the existing GAMA Model, while Phase III employs new parameters in the evacuation simulation.

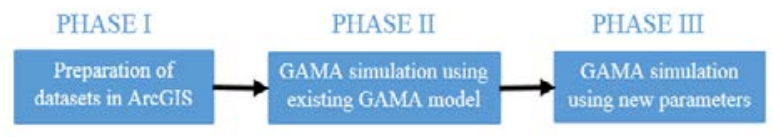

Figure 2. Workflow diagram for the three phases

\section{1 $\quad$ Phase 1}

The first phase involves the preparation of three-dimensional (3D) GIS model of the building. This involves collection of the building plans from the university campus architect, digitization, and extrusion to a 3D model. 


\subsubsection{Digitization using CAD Software}

The building footprint data from the Office of the Campus Architect (OCA) is manually delineated using AutoCAD software. Three main dataset features are created: the rooms as polygon datasets, the path networks as polylines, and the exits per floor as points. For the attributes of the data, elevation, room type, number of people per room, and width are taken into consideration.

\subsubsection{Creation of Layers in 3D}

Using the output from the delineated feature datasets from previous process, layers are then extruded to create a threedimensional model of the Kalayaan Building. This is done using tools in ArcScene.

\subsubsection{Testing of 3D Network}

To ensure that the created three-dimensional network is working, a test simulation is done. This represents the validation of the previous steps and is significant before implementing the agent-based simulation in GAMA. An established perfect run of network analysis is an indicator of a reliable three-dimensional model for GAMA testing.

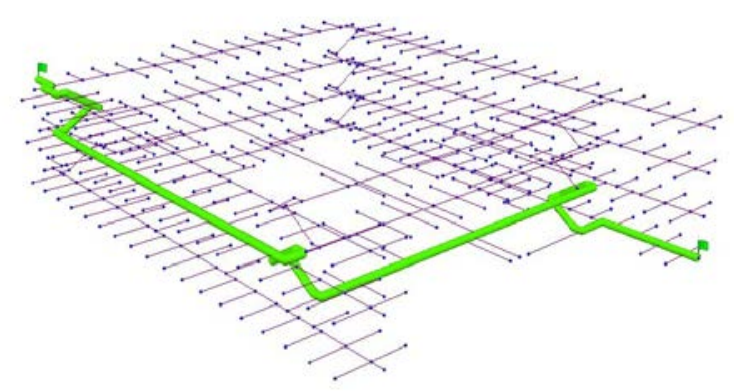

Figure 3. Network analysis testing in 3D

The polylines represent the path per corridor while the room centroids and exits are represented by nodes (points). Although not used in the network analysis testing, rooms and floors are represented by polygons.

\subsection{Phase 2}

The second phase delves on the implementation of the GAMA simulation using existing model. Using the datasets previously prepared from GIS platform, evacuation simulation is employed in the Kalayaan Residence Hall. The floor polygons, path networks, and exit points are used as feature inputs in the model.

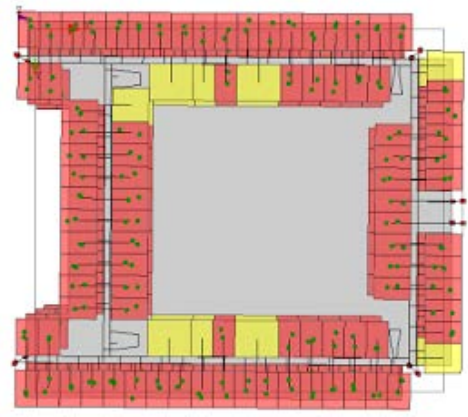

Figure 4. Importing of GIS database to GAMA Platform

\subsection{Phase 3}

The third phase employs new parameters in simulation. For the initial part of defining parameters, a quick survey was conducted with Kalayaan residents as respondents. Essentially we want to determine their knowledge of exits nearest to them and their response time given a set of situational parameters. These parameters include five states: In panic, sleeping, eating, in the Bathroom, and studying.

Response rate is from 1 to 9 where 1 corresponds slowest reaction time and 9 is the fastest reaction time, with 5 as a representation of no effect.

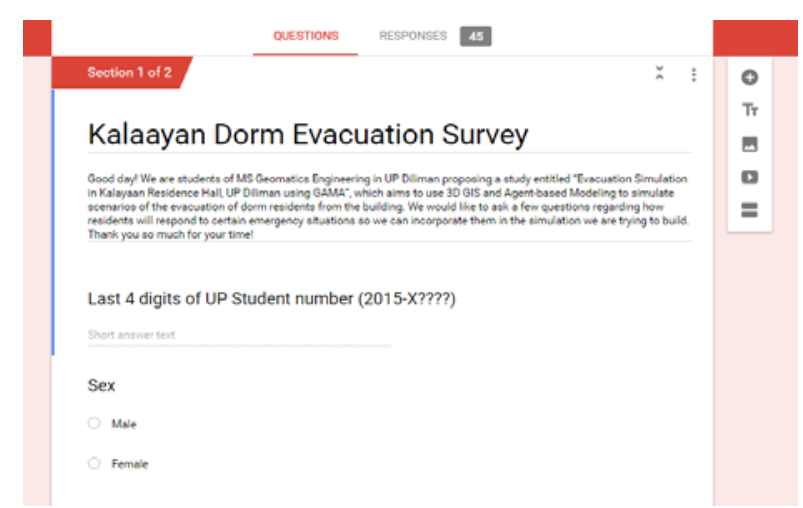

Figure 5. Interface of the online survey using Google Docs

\section{RESULTS AND DISCUSSIONS}

\subsection{Data Preparation and Information Extraction in GIS}

The data preparation and information extraction is done using ArcGIS. Parameters are initially defined in the attributes. These include the elevation of the floors, the number of people per room and the width of the corridors. These information were collected from the building plans and OSH.

Network paths and exit points should be consistent so as to avoid errors during the integration with the GAMA platform.

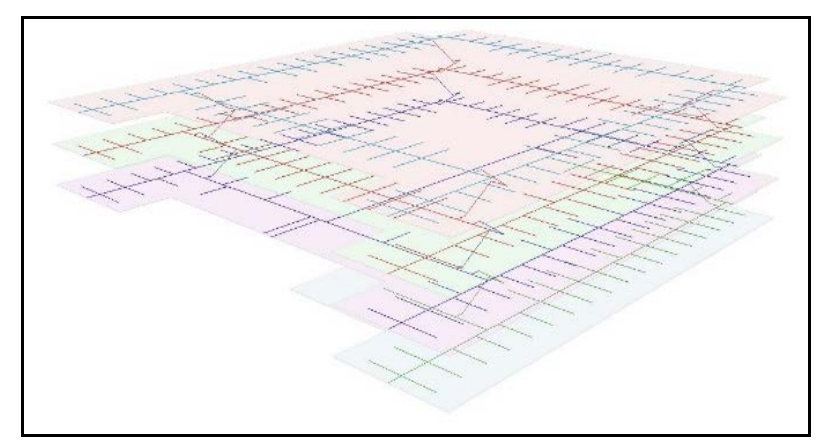

Figure 6. Kalayaan Dorm in three-dimensional platform

The polylines represent the network paths or the corridors and the polygons represent the rooms per floor. All in all, the Kalayaan Residence Hall has three floors and a basement, with a capacity of more than 500 residents. 
The International Archives of the Photogrammetry, Remote Sensing and Spatial Information Sciences, Volume XLII-4/W1, 2016 International Conference on Geomatic and Geospatial Technology (GGT) 2016, 3-5 October 2016, Kuala Lumpur, Malaysia

\subsection{Simulation in GAMA Software}

After the data preparation, GIS feature datasets were then incorporated in GAMA platform. For the test run, the program gets the number of agents per room from the predefined attributes and recreates it during the simulation.

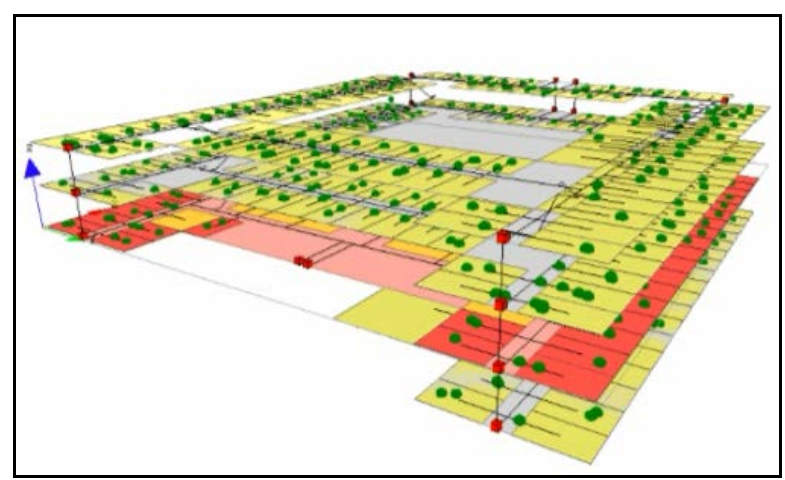

Figure 7. Evacuation simulation run in GAMA

The agents are represented by the green points inside the polygons. A counter is set such that the agents who reached the exit points are tallied as 'safe'. The evacuation time ends once the agents have reached these exit points.

The quantification of the evacuated agents can be visualized in a pie chart as the simulation progresses. The pie chart (Fig. 8) initially shows the distribution of the number of agents, per floor level. This the distribution changes as the simulation advances, denoting evacuation of agents through time. It has to be noted that for instance, the number of agents remaining for one floor may decrease, the adjacent floor's total might increase as the agents will pass through it if it deems necessary, and decrease again once the agents reach the exit. A line graph (Fig. 9) also visualizes the agent evacuated per time interval. Both illustrations are shown below.

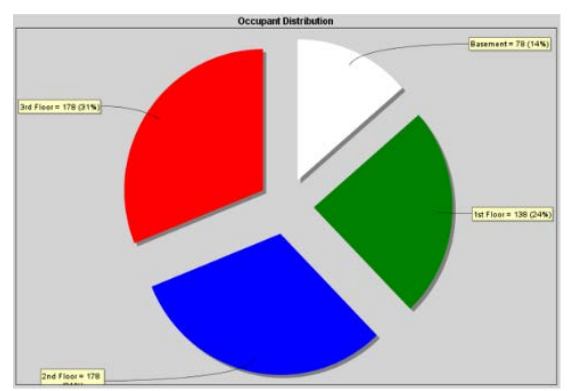

Figure 8. Pie Chart visualization of the GAMA simulation

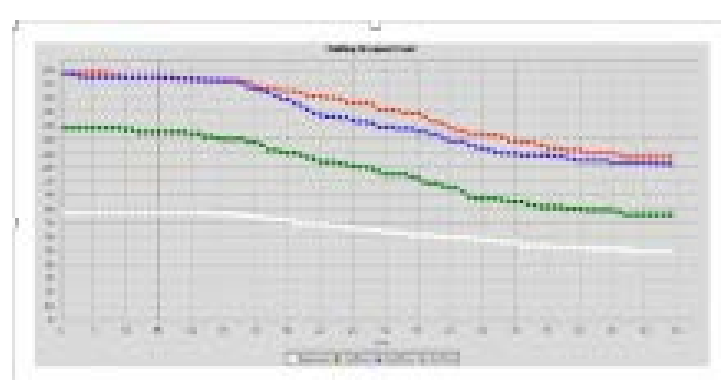

Figure 9. Line Chart visualization of the GAMA simulation

\subsection{Results and Implications}

The values for the evacuated agents per evacuation time are tabulated in each parameter case. As expected, activity parameters which include state of panic and studying would result to faster response time. Whereas activities such as sleeping and in bathroom yields the slowest response time. The summary of tabulated values is shown below.

\begin{tabular}{|c|c|c|c|}
\hline & $\begin{array}{c}\text { Activity } \\
\text { Effect }\end{array}$ & $\begin{array}{c}\text { Evacuated } \\
\text { Agents }\end{array}$ & Minutes \\
\hline $\begin{array}{c}\text { Original } \\
\text { State }\end{array}$ & 1 & 203 & 1.77 \\
\hline $\begin{array}{c}\text { State of } \\
\text { Panic }\end{array}$ & 1.219 & 228 & 1.46 \\
\hline Sleeping & 0.952 & 243 & 1.90 \\
\hline Eating & 1.116 & 240 & 1.55 \\
\hline Bathroom & 0.886 & 248 & 1.92 \\
\hline Studying & 1.239 & 226 & 1.43 \\
\hline
\end{tabular}

Table 1. Summary of values for each parameter simulation

To ensure consistency of the results, another simulation is ran wherein the time is set to a constant value of one minute. This is to quantify the number of evacuated agents.

\begin{tabular}{|c|c|c|c|}
\hline & $\begin{array}{c}\text { Activity } \\
\text { Effect }\end{array}$ & $\begin{array}{c}\text { Evacuated } \\
\text { Agents }\end{array}$ & Minutes \\
\hline $\begin{array}{c}\text { Original } \\
\text { State }\end{array}$ & 1 & 141 & 1 \\
\hline $\begin{array}{c}\text { State of } \\
\text { Panic }\end{array}$ & 1.219 & 167 & 1 \\
\hline Sleeping & 0.952 & 140 & 1 \\
\hline Eating & 1.116 & 160 & 1 \\
\hline Bathroom & 0.886 & 120 & 1 \\
\hline Studying & 1.239 & 191 & 1 \\
\hline
\end{tabular}

Table 2. Summary of evacuated agents per activity parameter at time $=1$ minute

Another simulation trial was done by doubling the value of the corridor width. As shown by the graph below, doubling the width would decrease their response time by half, therefore, evacuating the building twice as faster as compared to evacuation in a normal corridor width.

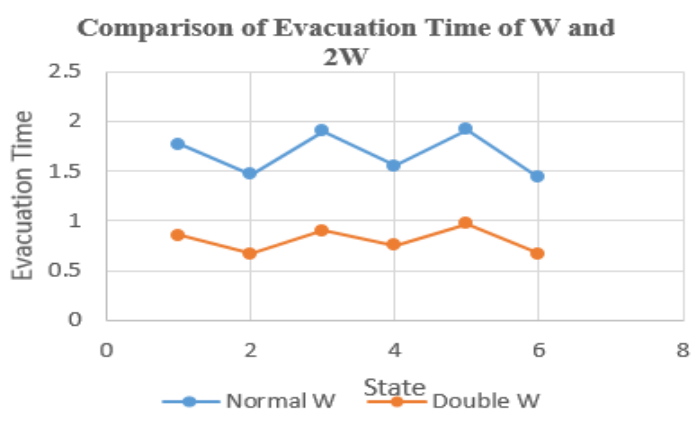

Figure 12. Comparison of corridor width and resulting evacuation time

\section{CONCLUSIONS AND RECOMMENDATIONS}

\subsection{Conclusions}

This study focuses on the use of GAMA as an agent-based platform for simulation. Specifically, this study implements 
an existing GAMA model in Kalayaan Residence Hall for a multi-agent based evacuation simulation.

One of the advantages of using GAMA platform with GIS platform is that they can easily be integrated. This is because GIS database is compatible with GAMA platform, hence, direct import of GIS datasets is feasible.

From the results of the simulation, GAMA can be a significant tool in modelling evacuation scenarios, specifically in a three-dimensional perspective. Requiring actual movement of people for preparations for events such as fire or earthquakes using drills can be minimized by employing similar simulations on structures.

Projecting these scenarios into a three-dimensional space results to a better visualization of the events.

\subsection{Recommendations}

For this study, network paths are modelled from polyline datasets. This results to an assumption that the agents are evacuating in a linear path and in a queue. Modelling the network paths in polygons would take into consideration a nonlinear scheme of evacuation.

For future works, it is highly recommended that more scientific basis in the behavioral aspect of agents is incorporated. This study does not focus on the social aspect and interaction of the agents but on the parameter activity and response time.

\section{ACKNOWLEDGEMENTS:}

The researchers would like to thank Dr. Ariel C. Blanco for his immense contribution for the completion of this research, to the University of the Philippines Campus Architect and Office of Student Housing for the datasets, and the resident assistants of the Kalayaan Dormitory (AY 2015-16) for assistance in the distribution of our survey materials.

\section{REFERENCES:}

"Emergency Response Plan-Student Affairs - Carnegie Mellon University." Emergency Response Plan-Student Affairs - Carnegie Mellon University. N.p., n.d. Web. 31 May 2016. <http://www.cmu.edu/studentaffairs/theword/comm_standards/response.html>.

Zarboutis, Nikos, and Nicolas Marmaras. "Design of Formative Evacuation Plans Using Agent-based Simulation." Safety Science 45.9 (2007): 920-40. Web.

Chen, X., and F. B. Zhan. "Agent-based Modelling and Simulation of Urban Evacuation: Relative Effectiveness of Simultaneous and Staged Evacuation Strategies." J Oper Res Soc Journal of the Operational Research Society 59.1 (2006): 25-33. Web.
"Principles and Concepts of Agent-Based Modelling for Developing Geospatial Simulations." Academia.edu. Centre for Advanced Spatial Analysis University College London, Sept. 2006. Web. 27 May 2016.

Macal, Charles M., and Michael J. North. "Introduction to Agent-based Modeling and Simulation." Center for Complex Adaptive Agent Systems Simulation (CAS2). Decision \& Information Sciences Division, Argonne National Laboratory, Argonne, IL 60439 USA. 29 Nov. 2006. Lecture. http://www.mcs.anl.gov/ leyffer/listn/slides-

06/MacalNorth.pdf

Macatulad, Edgardo G. "3D GIS Based Multi-Agent Geosimulation Model for Building Evacuation." Thesis. National Graduate School of Engineering, University of the Philippines - Diliman, 2015. Print.

Macatulad, E. G., and A. C. Blanco. "3DGIS-Based MultiAgent Geosimulation and Visualization of Building Evacuation Using GAMA Platform." Int. Arch. Photogramm. Remote Sens. Spatial Inf. Sci. ISPRS - International Archives of the Photogrammetry, Remote Sensing and Spatial Information Sciences XL-2 (2014): 87-91. Web.

"Kalayaan Residence Hall." IskWiki. University of the Philippines Office of the Vice Chancellor for Academic Affairs, 28 Oct. 2012. Web. 27 May 2016.

"Office of Student Housing." UP Office of the Vice Chancellor for Student Affairs. University of the Philippines Office of the Vice Chancellor for Student Affairs, n.d. Web. 27 May 2016.

Zheng, Xiaoping, Tingkuan Zhong, and Mengting Liu. "Modeling Crowd Evacuation of a Building Based on Seven Methodological Approaches." Building and Environment 44.3 (2009): 437-45. Web.

Chen, Xuwei, John W. Meaker, and F. Benjamin Zhan. "Agent-Based Modeling and Analysis of Hurricane Evacuation Procedures for the Florida Keys." Nat Hazards Natural Hazards 38.3 (2006): 321-38. Web.

Shi, Jianyong, Aizhu Ren, and Chi Chen. "Agent-based Evacuation Model of Large Public Buildings under Fire Conditions." Automation in Construction 18.3 (2009): 33847. Web.

"GAMA- Modeling Made Easy." N.p., 27 May 2015. Web. $30 \quad$ May $2016 . \quad<$ https://github.com/gamaplatform/gama/wiki>.

Taillandier, Patrick, Duc-An Vo, Edouard Amouroux, and Alexis Drogoul. "GAMA: A Simulation Platform That Integrates Geographical Information Data, Agent-Based Modeling and Multi-Scale Control." Principles and Practice of Multi-Agent Systems Lecture Notes in Computer Science (2012): 242-58. Web. 